\title{
A STUDY ON DRUG USE PATTERN USING WHO PRESCRIBING INDICATORS
}

\author{
Rezarta Shkreli ${ }^{1}$, Klodiola Dhamo ${ }^{2}$ and Afrim Tabaku ${ }^{3}$ \\ ${ }^{1}$ University Aldent, Faculty of Medical Sciences, Department of Pharmacy, Tirana, Albania, \\ Mobile +355 692355 145, e. mail: rezarta.shkreli@ual.edu.al \\ ${ }^{2}$ University Aldent, Faculty of Medical Sciences, Department of Pharmacy, Tirana, Albania, \\ Mobile:+355692265 255, e. mail: klodiola.dhamo@ual.edu.al \\ ${ }^{3}$ University Aldent, Faculty of Medical Sciences, Pharmacotherapeutics Research Centre, \\ Tirana, Albania, Mobile: +355 692469 518, e. mail: afrim.tabaku@ual.edu.al
}

\section{Abstract}

To promote rational drug use in developing countries, it is important to assess drug use pattern using the World Health Organization (WHO) drug use indicators. The aim of this study was to assess the drug prescription patterns and the extent of rational prescribing in Tirana city, Albania.

A descriptive, cross-sectional, retrospective study of 1000 prescriptions, selected by systematic random sampling from 5000 prescription collected in 8 pharmacies in Tirana was conducted at the outpatient pharmacy. The WHO prescribing indicators were analyzed using the SPSS package 21 . The index of rational drug prescribing (IRDP) was calculated to assess rational prescribing. The average number of medicines per prescription was 2.406 . The percentage of medicines prescribed by generic names was $43.85 \%$, while $53.3 \%$ and $10.3 \%$ of prescriptions had an antibiotic and injection, respectively. The percentage of medicines prescribed from the national essential medicines list was $24.10 \%$. The most commonly prescribed pharmacological groups of medicines were antibiotics $51.5 \%$, vitamins $49.4 \%$ and NSAIDS $22.70 \%$. The IRDP was 2.728, instead of the ideal value of 5. Average number of medicines per prescription, prescription with generic name and drug from the essential medicines list, and IRDP showed deviation from the standard recommended by WHO. However, there is a need to do more on some issues, including prescribing practice of antibiotics, average number of medicines per prescription, as well as prescribing by national essential of medicine list and by generic names.

Key word: Antibiotics, injections, rational prescribing, inappropriate prescribing, essential medicines list, WHO core drug use indicators

Corresponding Author: Afrim Tabaku

\section{INTRODUCTION}

Medicines play an important role in health care delivery and disease prevention (Ehijie et al, 2011). In the present days, irrational drug use is a major health problem. Irrational drug use is a global health problem that leads to ineffective and unsafe treatment, prolongation of illness, harm to the patients and higher cost of the drugs, adverse drug reactions, development of resistance to antibiotics. (Haldar et al, 2011).

Worldwide, more than half of all medicines are prescribed, dispensed, or sold improperly, and $50 \%$ of patients fail to take them correctly. The common problems of inappropriate use of medicines include: polypharmacy (use of too many medicines), overuse of antibiotics and injections, failure to prescribe in 
accordance with clinical guidelines, inappropriate self-medication and failure of patients to take their medicines correctly (WHO 2002).

Moreover, about one third of the world's population lacks access to essential medicines (Teferra et al, 2002). Essential drug ones selected to fulfill the real need of the majority of the population in diagnostic, prophylactic, therapeutic and rehabilitative services using criteria of risk benefit-ratio, cost effectiveness, quality practical administration as well as patient compliance and acceptance (Hogerzeil 1995)

Studies done in different areas of the world reveal different drug use patterns (Desta et al 1997, Dikaso et al 1998, Mallet et al 2001, and Otoom et al 2002, Moro \& Marchi 2009, Holstiege. \&. Garbe, 2013, Hovstadius et al 2010, Jaafer 2007).

Irrational prescribing patterns are perpetuated through patient pressure, bad example of colleagues, and high-powered salesmanship by drug company representatives. The consequences of irrational use of medicines include significant patient harm in term of poor patient outcome and significant Adverse Drugs Reactions (ADRs), development of antimicrobial resistance, waste of resources and economic burden on patient and society (WHO 2002).

Two of the most commonly seen irrational use of medicines in developing countries is excessive use of antibiotics and injections. The development of resistant microbes will remain as a problem whenever antimicrobials are used.

Assessment of drug use patterns with the WHO drug use indicators is becoming increasingly necessary to promote rational drug use in developing countries (Hogerzeil et al, 1993; WHO 1993).

To improve the overall drug use, especially in developing countries, international agencies like the WHO and the International Network for the rational use of drugs (INRUD) are carrying out studies to develop standard drug use indicators (Biswas et al, 2001).

In order to describe the drug use situation in health facilities, WHO developed a set of standardized drug use indicators which can provide a basis for planning and implementation of rational medicine use strategies if any problems are identified. Specifically, the prescribing indicators are useful in identifying problems in general prescribing.

The conference of experts which had been held in Kenya in 1985 developed the road map for improving the rational use of medicines and defined it as: patients receive medications appropriate to their clinical needs, in doses that meet their own individual requirements, for an adequate period of time, and at the lowest cost to them and their community, and is characterized by: appropriate indication, appropriate medicine, appropriate patient, appropriate information and appropriate monitoring.

The aim of this study was to identify the drug use pattern and to evaluate the rationality of the prevalent practices among using various $\mathrm{WHO}$ prescribing indicators.

\section{MATERIALS AND METHODS}

A cross sectional study was carried out retrospectively, between September 2017 and February 2018, in eight randomly selected pharmacies in urban area of Tirana city. Out of 5000 prescriptions selected by using random method, we chose to examine 1000 prescriptions. 
WHO prescribing indicators (average number of medicines prescribed per patient encounter, percentage of drugs prescribed by generic name, percentage of encounters with an antibiotic prescribed, percentage of encounters with an injection prescribed and percentage of medicines prescribed from the National Essential Medicines List and pharmacological classes of medicines prescribed, were analyzed using the Statistical Package for Social Sciences (SPSS) version 21.

IRDP was determined by adopting a previously validated method (Zhang \& Zhi 1995). It consists of five indices derived from the WHO prescribing indicators. Data obtained by this study, together with the optimal level for each indicator (De Joncheere 2002: Melander 2002) is shown Table 1

Each of the five prescribing indicators has an optimal index of 1; the closer to 1 the calculated index is, the more rational prescribing is considered to be. The index of polypharmacy was measured by the percentage of nonpolypharmacy prescriptions; in this study, those prescriptions with two or less medicines where considered as nonpolypharmacy. The generic name index and essential medicine index were measured by the percentage of drugs prescribed by generic name and from the National Essential Medicines List (NEML) respectively. The index of rational antibiotic prescribing was defined as dividing the optimal level (30\%) by the percentage of

prescriptions including antibiotic. The index of safety injection was calculated by dividing the optimal level $(10 \%)$ by the percentage of prescriptions including the injection. The index of rational drug prescribing (IRDP), which has a maximum value of 5 , can then be calculated by adding the indices.

\section{Results}

During the study period a total of 2406 drug products were prescribed in the sample of 1000 prescriptions. The average number of medicines per encounter was 2.406 ( $\mathrm{SD} \pm 1.1395)$ ranging from 1 to 8 . The majority of prescriptions (43.50\%) were prescribed with more than 2 drugs and $24.10 \%$ prescribed from the NEML. NEML is approved in our country in 1993 and had a limited number of medicines and it is no updated anywhere. Fifty one percent $51.5 \%$ and $10.3 \%$ of the encounters had at least an antibiotic and an injection prescribed respectively. (Table1 and graph1).

\section{Table 1}

Data obtained for prescribing indicators, their optimal level and optimal index

\begin{tabular}{|l|c|c|c|}
\hline Prescribing indicators assessed & $\begin{array}{l}\text { Obtained data } \\
\text { of this study }\end{array}$ & $\begin{array}{l}\text { Optimal level\% } \\
\text { De Joncheere 2002 }\end{array}$ & $\begin{array}{l}\text { Optimal index } \\
\text { De Joncheere 2002 }\end{array}$ \\
\hline $\begin{array}{l}\text { Average number of drugs per } \\
\text { encounter }\end{array}$ & $2.406 \pm 1.1395$ & $\leq 2$ & 1 \\
\hline $\begin{array}{l}\text { Percentage of drugs prescribed by } \\
\text { generic name }\end{array}$ & $43.85 \%$ & 100 & 1 \\
\hline $\begin{array}{l}\text { Percentage of encounters with } \\
\text { antibiotics prescribed }\end{array}$ & $51.5 \%$ & $\leq 30$ & 1 \\
\hline $\begin{array}{l}\text { Percentage of encounters with } \\
\text { injections prescribed }\end{array}$ & $10.3 \%$ & $\leq 10$ & 1 \\
\hline $\begin{array}{l}\text { Percentage of drugs prescribed } \\
\text { from Essential Medicines List }\end{array}$ & $24.10 \%$ & 100 & 1 \\
\hline
\end{tabular}




\section{Graph 1}

\section{Number of drugs per encounter}

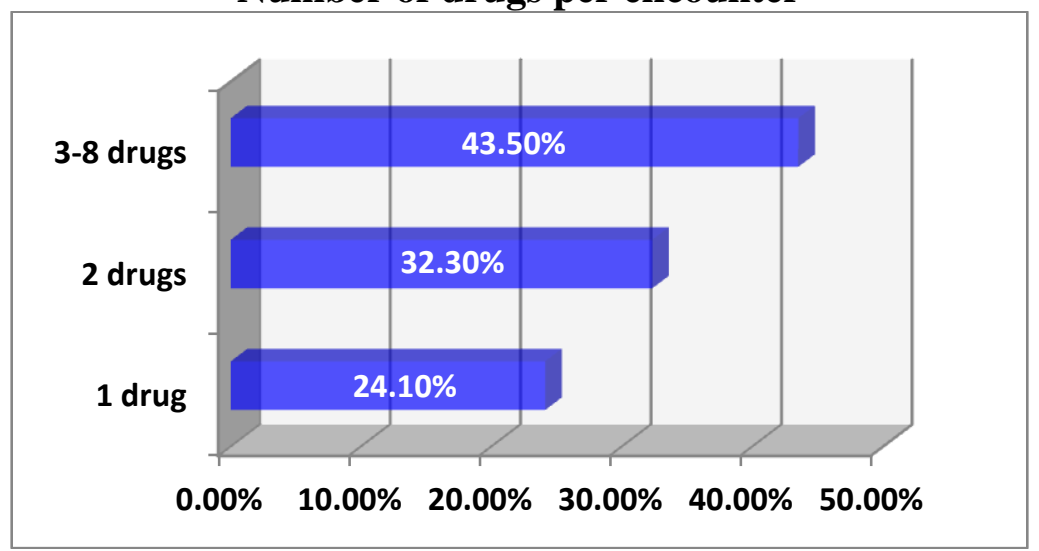

\section{Graph 2}

\section{Number of drugs prescribed in brand/generic name}

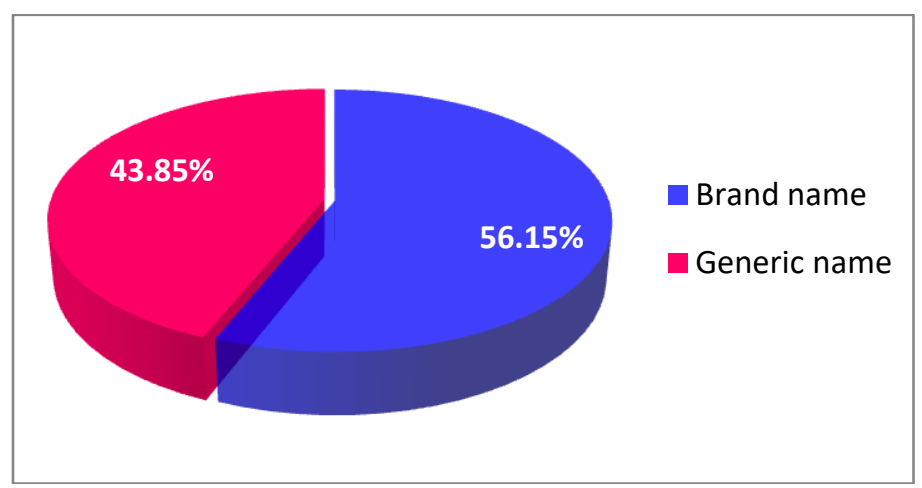

As shown in graph 2 the brand prescribing have resulted $56.15 \%$ whereas those prescribed as generics were $43.85 \%$.

\section{Graph 3}

\section{Classes of antibiotics commonly prescribed}

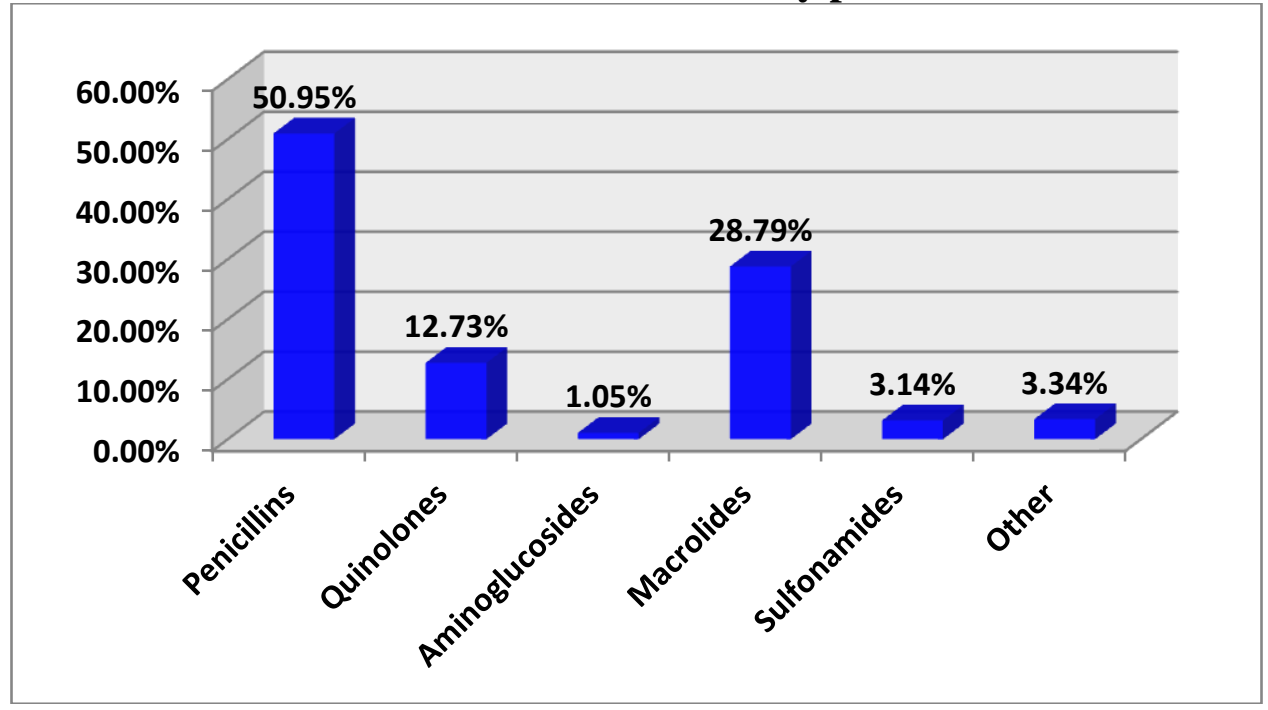


The percentage of encounters in which antibiotics prescribed were 51.5\%. The most commonly classes of antibiotics prescribed were penicillins $50.95 \%$, macrolides $28.79 \%$ and quinolones $12.73 \%$.

The most commonly prescribed antibiotics from class of penicillins were amoxicillin $169(57.87 \%)$, cefaclor $31(10.61 \%)$ and ceftriaxone 26 (8.90\%); from macrolides were azithromycin $64(38.78 \%)$, doxacycline $44(26.66 \%)$, clarithromycin $28(16.96 \%)$ and from quinolones class were ciprofloxacin 43 $(58.90 \%)$ and levofloxacine $20(27.39 \%)$

$10.3 \%$ of the prescriptions had at least an injection prescribed. The most commonly prescribed injections are presented in table 2

\section{Table 2}

\section{Commonly prescribed injections}

\begin{tabular}{|l|c|c|}
\hline Commonly prescribed injections & Frequency & Percent \\
\hline Ceftriaxone & 26 & $28.2 \%$ \\
\hline Methyl prednisolone & 11 & $11.9 \%$ \\
\hline Chorionic gonadotropin & 9 & $9.78 \%$ \\
\hline Piroxicam & 6 & $6.52 \%$ \\
\hline Gentamicin & 4 & $4.35 \%$ \\
\hline Prednisolone & 3 & $3.26 \%$ \\
\hline Ampicillin & 2 & $2.17 \%$ \\
\hline Ciprofloxacin & 2 & $2.17 \%$ \\
\hline Amikacin & 2 & $2.17 \%$ \\
\hline Multivitamins & 2 & $2.17 \%$ \\
\hline
\end{tabular}

Graph 4

Pharmacological classes of medicines prescribed

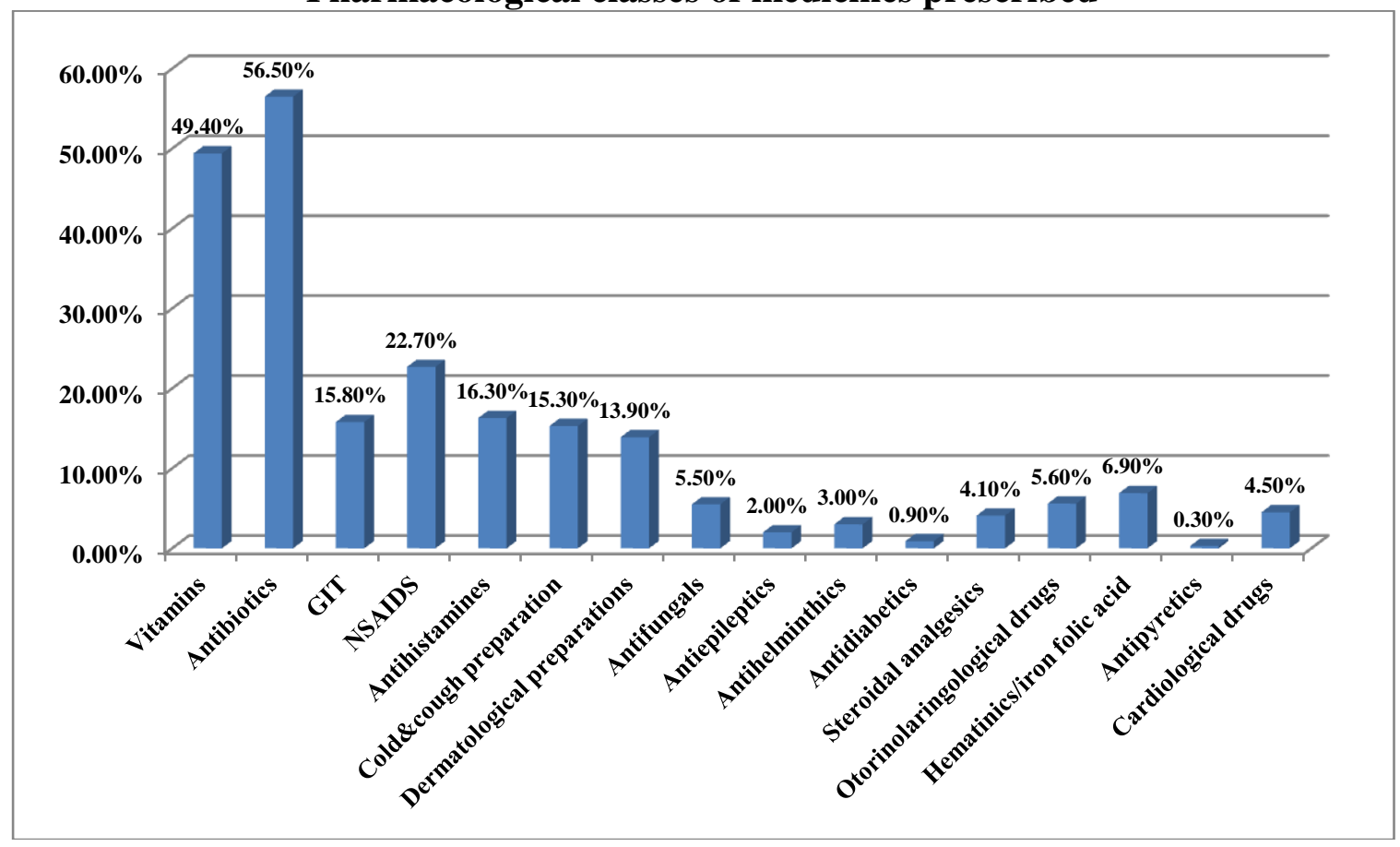




\section{Table 3}

\section{Distribution of commonly prescribed drugs by the practitioners}

\begin{tabular}{|l|c|c|}
\hline Classes of medecines & Frequency & Percent \\
\hline Vitamins & 494 & 49.4 \\
\hline Antibiotics & 568 & 56.8 \\
\hline Drugs for GIT & 158 & 15.8 \\
\hline NSAIDS & 227 & 22.7 \\
\hline Antihistamines & 163 & 16.3 \\
\hline Cold \& cough preparation & 153 & 15.3 \\
\hline Dermatological preparations & 139 & 13.9 \\
\hline Antifungal & 55 & 5.5 \\
\hline Antiepileptic & 20 & 2.0 \\
\hline Anti-helminthes & 3 & 0.3 \\
\hline Anti-diabetics & 9 & 0.9 \\
\hline Steroidal analgesics & 41 & 4.1 \\
\hline Otorinolaringological drugs & 56 & 5.6 \\
\hline Hematinics/iron folic acid & 69 & 6.9 \\
\hline Antipyretics & 3 & 0.3 \\
\hline Cardiological drugs & 45 & 4.5 \\
\hline
\end{tabular}

Regarding pharmacological class of medicines prescribed the most prescribed medicines were antibiotics (56.80\%), vitamins (49.4\%), NSAIDS (22.7\%), antihistamines (16.3\%) and cough and cold preparation $(15.3 \%)$. Graph 4 shows the different classes of medicines obtained from this study.

IRDP used as an indicator of rational drug use was 2.728 . Antibiotic prescribing, polypharmacy and injection prescribing had the indices of $0.56,0.465$ and 0.97 , respectively, whereas the generic prescribing and essential medicines had the lowest indices.

\section{Table 4}

\section{Index of rational drug prescription}

\begin{tabular}{|l|c|}
\hline Indexes of rational drug prescription & Results \\
\hline Index of polypharmacy & 0.564 \\
\hline Generic prescribing index & 0.438 \\
\hline Index of rational antibiotic prescribing & 0.515 \\
\hline Index of rational injection prescribing & 0.97 \\
\hline Essential medicines index & 0.241 \\
\hline Index of rational drug prescribing (IRDP) & 2.728 \\
\hline
\end{tabular}

\section{Discussions}

Medicines play a crucial role in improving the health outcome of population. However, improved access to quality medicines is not enough to get benefit from medicines, and also the appropriate use which has become a global concern. 
World Health Organization developed a core prescribing indicators to measure the degree of polypharmacy, the tendency to prescribe drugs by generic name and the overall level of use of antibiotics and injections. The degree to which the prescribing practice conformed to the essential drug list, formulary or standard treatment guideline, were also measured by searching for the number of drugs prescribed from essential drug list available (WHO, 2002).

Accordingly, the result of this study revealed that the average number of drugs per encounter was 2.4 which is higher of WHO standards that is less than or equal to 2 (WHO, 2002; WHO, 1993). The values reported in this study are more or less similar with some studies carried out in developing countries (Otoom, 2002, Acurcio et al, 2004, Mhetre et al, 2003, Bimo 1992). Even though there are no adequate studies that identify the reasons for polypharmacy in the study area, it might be related to lack of adequate training of health professionals, variation in the health care delivery system, differences in socioeconomic profiles as well as morbidity and mortality characteristics of the population.

The percentage of encounters in which antibiotics were prescribed was $51.5 \%$ which is very high compared to the standard (20.0\%-26.8\%) derived to be ideal (WHO, 2002; WHO 1993). This finding suggests that antibiotic prescribing needs to be regulated. This increasing use of antibiotics not only leads to the increased cost of therapy, but also to increased incidence of ADRs and to the selection of drug resistant bacterial strains. The high percentage of antibiotics prescribed in our study setting can be due to the cultural benefits about antibiotics or the patients' expectation to receive antibiotics.

In the drug use pattern study in 12 developing countries, the percentage of encounters in which an antibiotic was prescribed was high in Sudan (63\%), Uganda (56\%), and Nigeria (48\%) and relatively better in Zimbabwe (29\%) (Bannenberg et al,1991; Christensen 1990). Besides, similar studies in Yemen, western China, and Nepal reported the percentage of encounters in which an antibiotic was prescribed as 66.2, 48.43, and 28.3\% respectively (Ghimire et al, 2009, Bashrahil 2010, Lifang 2011). A longitudinal study (Adriaenssens, Coenen et al. 2011) conducted in 25 European countries between 1997 and 2003, showed that, the volume of outpatient antibiotic use increased with high seasonal variation (increase of 30\% in the first and fourth quarters compared with the second and third quarters), and penicillins were the most prescribed outpatient antibiotics, while the use of cephalosporins, tetracyclines and sulphonamides remained the same or decreased, but quinolones increased.

In this study, the percentage of prescription with an injection encounter was $10.3 \%$ which is lower than the WHO standard 13.4-24.1\% (WHO 1993). In a prescription pattern study in 12 developing countries, the percentage of encounters in which an injection was prescribed was high in Uganda (48\%) and Sudan (36\%) but very low in Zimbabwe (11\%), and in the acceptable range in Indonesia (17\%), Ecuador (17\%), and Mali (19\%) (MoH Zimbabwe, 1993, Ofori-Adjei 1993, Bimo 1993, Christensen 1993).

Minimum use of injections is preferred as it reduces the risk of infection through parenteral route and cost incurred in therapy (Ghimire et al, 2009). The lower prevalence of injection in this study might be the cultural barriers against injection based treatment in the study area.

Our study also revealed that antibiotics, vitamins and NSAIDS were the most commonly prescribed pharmacological group of medicines for this group of patients.

Results obtained in this study have shown that most of drugs (56.15\%) were prescribed by their brand names and only $43.85 \%$ were prescribed by their generic names, which is lower than recommended by WHO. Prescribing the drugs with their brand name increases the cost of therapy to the patients. Increasing generic prescribing would rationalize the use and reduce the cost of drugs and also promote better communication among healthcare providers (WHO 1997) which is of great importance in developing countries like Albania, whereas on the other hand, using generic names also reduces confusion relating to drug names, costs and stock items. 
In the past decade, an increased trend in generic prescribing in developing and transitional countries has been observed (WHO, 2009).

The percentage of medicines prescribed from the essential medicine list for this study was $24.10 \%$, which is lower than the standard (100\%) (WHO 2009). National essential medicine list was approved in our country in 1993 and had a limited number of medicines and it was never updated. In the last 25 years, in Albanian pharmaceutical market have entered a lot of medicines that are not prescribed in NEML.

Use of the drugs from the essential drug list should be promoted for the optimal use of limited resources, for maximum safety and to satisfy the health care needs of the majority of the population. Selection of the essential drugs should be done based on the changing epidemiological conditions, as well as considering the progress in the pharmacological and pharmaceutical knowledge. Prescribing from an essential medicine list has also increased progressively over the past 25 years globally (WHO 2009).

The strength of this study is that it provides baseline information on rational prescribing to which future assessments can be compared when monitoring prescribing trends and providing interventions if needed, whereas the weakness is the limited number of pharmacies that are included in this study.

\section{Conclusions}

On the basis of the findings of this study, the prescribing practices for antibiotics, average number of medicines per prescription, prescription with generic name and drug from the essential medicines list, showed deviation from the standard recommended by WHO. Baseline data gathered by this study can be used by researchers and policymakers to improve prescribing practice. Also, it is a urgent needs to update the National Essential Medicines List.

\section{References}

I Ehijie F.O. Enato and Ifeanyi E. Chima, Evaluation of drug utilization patterns and patient care practices, West African Journal of Pharmacy 2011, 22 (1): 36 - 41

II Haldar D, Naskar TK, Sarkar TK, Ray SK, Taraphdar P, Biswas, A Prescribing and dispensing pattern: Implication in the right of access to essential medicine, The Health. 2011; 2(4): 143147

III WHO (2002). "Promoting rational use of medicines: core components." WHO Policy Perspectives on Medicines

IV Teferra A, Zeruesenay D, Asfawossen GY, Prescribing Pattern of Drugs in Medical Wards of Three Hospitals in North-West Ethiopia, Journal of Ethiopian Medical Practice 2002; 4: 8-13

V Hogerzeil HV, Bimo, Ross-Degnan D, Laing RO, Ofori-Adjei D, Santoso B, Azad Chowdhury AK, Das AM, Kafle KK, Mabadeje AF: Field tests for rational drug use in twelve developing countries. Lancet 1993, 342(8884): 1408-1410.

VI Biswas NR, Jindal S, Siddiquei MM et al, Patterns of prescription and drug use in ophthalmology in a tertiary hospital in Delhi, British Journal of Clinical Pharmacology, 2001, 51: $267-269$

VII WHO: How to investigate drug use in health facilities: selected drug use indicators. Geneva: WHO/DAP/93.1; 1993

VIII Desta Z, Abula T, Beyene L, Fantahun M, Gebre-Yohannes A, Ayalew S. Assessment of rational drug use and prescribing in primary health care facilities in north west Ethiopia. East African medical journal, 1997, 74:758-63 
IX Dikaso D, Gobe Z, Teklemariam S. A base line survey on prescribing indicators and underlying factors influencing prescribing in southern Ethiopia, Ethiopia .J. health Dev, 1998;12 (2) 87-93

$\mathbf{X}$ Mallet H.P., Njikam A, and Scouflaire S.M. Evaluation of prescription practices and the rational use of medicines in Niger, Niger pharmaceutical Journal; 2001; 11 (3); 185- 96

XI Otoom S, Batieha A, Hadidi H, Hasan M, Al-Saudi K. Evaluation of drug use in Jordan using World Health Organization prescribing indicators. Eastern Mediterranean Health Journal, 2002, 8:000-000

XII Moro M, Marchi M, Gagliotti C, Mario S, Resi D (2009). "Why do paediatricians prescript. Results of an Italian regional project." BMC pediatrics 9(1): 69

XIII Holstiege, J. and E. Garbe (2013). "Systemic antibiotic use among children and adolescents in Germany: a population-based study." European Journal of Pediatrics: 1-9.

XIVHovstadius B, Hovstadius K, Astrand B, Petersson G (2010). "Increasing polypharmacy-an individual based study of the Swedish population 2005-2008." BMC Pharmacology and Toxicology 10(1): 16

XV Jaafer, B. (2007). National Approach to Promote Rational Use of Medicines. World Health Assembly. Geneva.

XVI Hogerzeil HV. Promoting rational prescribing: an international perspective. $\mathrm{Br} \mathrm{J}$ Clin Pharmacol. 1995; 39(1): 1-6

XVII Zhang Y, Zhi M. Index system, appraising method for comprehensive appraisal. J North Jiaotong Univ 1995;19:393-400.

XVIII De Joncheere K. Implementation of Rational Pharmacotherapy. Meeting under Danish EU presidency. Perspectives and achievements with Rational Pharmacotherapy. Copenhagen Denmark, WHO/EURO; 2002.

XIX Melander A. Variation in drug utilization in the EU: Causes and consequences as illustrated by antibiotics. Meeting under Danish EU presidency. Perspectives and Achievements with Rational Pharmacotherapy. Copenhagen, Denmark: WHO/EURO; 2002

XX Acurcio FA, Perini E, Magalhaes SM, Terceiro LG, Vieira Filho JM, Coutinho KE, et al. Analysis of medical prescriptions dispensed at health centers in Belo Horizonte, Minas Gerais, Brazil. Cad Saude Publica. 2004;20:72-9.

XXI Mhetre NA, Bodhankar SL, Pandit VA, Zambare GN. Study of pattern of drug usage in an urban area. Indian J Pharmacol. 2003; 35:316-7.

XXII Bimo: Report on Nigerian field test. INRUD News 1992; 3(1): 9-10.In How to investigate drug use in health facilities. Geneva: WHO; 1993. 74(WHO/ DAP/93.1). http://apps.who.int/medicinedocs/en/d/Js2289e/8.3.html. Accessed 24 Feb 2014.

XXIII Bannenberg WJ, Forshaw CJ, Fresle D, Salami AO, Wahab HA: Evaluation of the Nile province essential drug project. WHO: Geneva; 1991. WHO/DAP/91.10. In: How to investigate drug use in health facilities. Geneva, WHO, 1993: 74 (WHO/DAP/93.1)

XXIV Christensen RF: A strategy for the improvement of prescribing and drug use in rural health facilities in Uganda. Ugandan Essential drugs and management program; 2 September-11 October 1990.In How to investigate drug use in health facilities. Geneva: WHO; 1993. 74(WHO/DAP/93.1)

XXV Ghimire S, Nepal S, Bhandari S, Nepal P, Palaian S. A prospective surveillance of drug prescribing and dispensing in a teaching hospital in Western Nepal. J Pak Med Assoc. 2009;59:726-31

XXVI Bashrahil KA. Indicators of rational drug use and health services in Hadramout, Yemen. East Mediterr Health J. 2010;16:151-5. 
XXVII Lifang D, Hong Y, Duolao W. Drug prescribing indicators in village health clinics across 10 provinces, of Western China. Fam Pract. 2011; 28:63-7

XXVIII Adriaenssens, N., S. Coenen, Versporten A, Muller A, Minalu G, Faes C, Vankerckhoven V, Aerts M, Hens N, Molenberghs G, Goossens H . (2011). "European Surveillance of Antimicrobial Consumption (ESAC): outpatient antibiotic use in Europe (1997-2009)." Journal of antimicrobial chemotherapy 66(suppl 6): vi3-vi12

XXIX Ministry of Health/Zimbabwe Essential Drugs Action Programme: Essential Drugs Survey. In How to investigate drug use in health facilities. WHO: Geneva; 1993. 74(WHO/DAP/93.1)

XXX Ofori-Adjei D: Report on Tanzanian field test. INRUD News; 3(1): 9. In How to investigate drug use in health facilities. WHO: Geneva; 1993.74(WHO/DAP/93.1)

XXXI Bimo: Field testing of drug use indicators of INRUD: report of field trip to Indonesia, Bangladesh, and Nepal, June-July 1991. In How to investigate drug use in health facilities. WHO: Geneva; 1993. 74(WHO/DAP/93.1)

XXXII WHO. Guidelines on the Use of INNs for Pharmaceutical Substances. Geneva: WHO Press; 1997

XXXIII WHO. Medicines Use in Primary Care in Developing and Transitional Countries. Fact Book Summarizing Results from Studies Reported Between 1990 and 2006. Geneva: WHO Press; 2009 